\title{
Do what the creator wants us to do
}

Volume 5 Issue 6 - 2017

\section{Opinion}

While men of religion believe that man is created by God and men of science believe that man is the product of natural evolution, the one fact both believe in is that man is not of his own making. Since life and its ecosystem are not designed by us, there must be the designer above us no matter we call him god or Mother Nature. Since the designer is superior to the designed, we have life; the designer must also have life. So, the Creator exists. We have senses and desires, he must have super senses and expectations; we have abilities, he must have super abilities. He must be much more powerful than man no matter how science and technology are developed and how high positions can be obtained in the human society. We must follow his way and do what he wants us to do, and then we can really enjoy living and this paradise with real good health and satisfaction.

What does the Creator want us to do? He gives everybody life and the natural environment and wants us to enjoy life (life's functions) in terms of his criteria of good health. Many people say no free lunch; in fact, life and natural environment are free. The saying "No free lunch" tells that the world does not know how to enjoy life and the natural environment, the most valuable things during life span. Enjoying life and enjoying life's conditions are confusing the world. Chasing GDP and wealth has overshadowed life's amazing functions, the most wonderful and enjoyable offers and possessions from the Creator.

Life has many automatic functions. They can automatically digest food, breath air, pump blood, distribute necessities to cells, diagnose itself, kill germs and viruses, repair itself at cell's level without scars, etc. Based on these automatic functions, the body is capable of handling disease attacks, predators' attacks, and mental threats and problems such as lack of confidence, unhappiness, etc. All wild species demonstrate the level of health and enjoyment of life, the Creator's criteria of health. At that level of health, the body becomes a wonderful hydraulic automation possession driven by internal energy flow.

Life's functions are highly organized and cooperated as a machine cannot miss a part and a puzzle cannot miss one piece. Since using primitive tools like stones for defense and hunting, man started to deviate from depending on the body's movement and the natural way of movement for survival. That movement way is highly cooperative with other functions of life inside the body. History of mankind, in certain perspective, is the history of using tools. From primitive tools like stones and branches to modern machinery, automobiles, weapons, pharmaceuticals, etc, dependence on conveniences has weakened human life and made us unable to survive in wild conditions without weapons and other tools' protection. Man has long lost the vigor, confidence, fun, and enjoyment of the real health that the Creator offers. Data showing that criminal rates, drug users, health problems increase with the development of technology and modernization actually tell the negative influence of tools on health physically and mentally.

As ball players using missiles or other tools to shoot balls will lose movement abilities, mankind depending on tools has long lost the original level of movement abilities, health, and enjoyment. As the result, the more dependent on conveniences, the more we need to work hard to add artificial things and conveniences. Is it convenient to work one third of one day and five days one week? Is it convenient to depend on artificial conveniences instead of the Creator's offers? In this sense, with the Creator's criteria in mind, we can discover that life's functions have no substitutes. It is the fact that nobody can hire someone else to eat, digest, sleep, etc, and we cannot depend on tools either to do the body's jobs and life's functions. Different sense organs have different functions and cannot substitute for each other either. There is no way to use eyes to enjoy food or use ears to watch movies. Modern medicine tries to use eyes through anatomy, instruments, and physiology to do internal sense organs' jobs to understand life. That makes modern medicine lose the vivid living awareness and do not understanding life. Modern medicine also tries to do the body's jobs and kill disease with surgery and pills. That causes the health care expenditure skyrocketing and no way to achieve the criteria of the Creator.

All human-designed products can be classified to tools. House, cars, and money are examples. Though they are supposed to be good for health, happiness, and satisfaction, the conveniences actually try to do the body's jobs and weaken life's functions unconsciously.

Take America as an example, having achieved high level of living conditions, the country needs more, one quarter of GDP for health care and medicine. That tells no way to do the body's jobs (life's functions) and man has become so dependent and sick in terms of the criteria of the Creator. The general sickness of mankind in terms of the Creator's criteria is the base and main cause of most human disease and social problems. The answer lies in the Creator's offers. We have to let life's functions kill disease. Indeed, many people are working on the body for health and fitness. However, as not all keys can unlock a door, not all exercises and movement can match life's functions and lead to achieve the Creator's criteria. Only the movements that the Creator designs can lead to the Creator's criteria and let life's functions powerful enough to kill disease without medicine, handle predators without weapons, keep vigor and confidence in the wild conditions. This level of health and enjoying life are much higher than no disease, the current goal of medicine. As mountain climbers must keep the top 
peak as the goal for their right pass, government, university, hospital, and church must keep the Creator's criteria as the right goal for the right policies and the right way for progress.

Evolution and creation have been put forward for many years, while the Creator's criteria for natural selection and/or creation have not been recognized. The world is still confused about money is for life or life is for money. Life, its functions are much more valuable, enjoyable, and beneficial than artificial products and wealth. Thanks to the great founders of America, human rights endowed by the Creator have been recognized. However, in addition to human rights, human responsibilities and other species' life's rights have not yet. Let us add human responsibilities to human rights and extend human rights to life's rights for all species. When all species' life rights are respected, responsibilities from all species including us will contribute to real good health and the natural environment, we will see that this planet is right the paradise!

\section{Acknowledgments}

None.

\section{Conflicts of interest}

Author declares there are no conflicts of interest.

\section{Funding}

None. 